\title{
O DESAFIO DA CONCEPÇÃO DE CURSO NA MODALIDADE DE EDUCAÇÃO A DISTÂNCIA PARA EDUCAÇÃO PERMANENTE ATRAVÉS DO USO DA METODOLOGIA DA PROBLEMATIZAÇÃO
}

\author{
Ana Amélia Nascimento da Silva Bones- anageriatra@ hotmail.com -UFCSPA \\ Silvio César Cazella- silvio.cazella@gmail.com -UFCSPA \\ Márcia Rosa da Costa- marciarc.ufcspa@gmail.com -UFCSPA, UNASUS/UFCSPA
}

Resumo. A metodologia da problematização constitui-se em uma metodologia ativa, que possibilita potencializar a capacidade do aluno no que se refere a sua postura de agente de participação e transformação social, na detecção de problemas reais e busca de soluções originais e criativas. Para investigar o uso da metodologia da problematização na modalidade a distância em educação permanente, foi desenvolvido um curso sobre o tema HIV para profissionais da saúde com foco na prática social. Este artigo apresenta o desafio que se constitui o uso da metodologia da problematização na modalidade de educação à distância na educação permanente, descrevendo e analisando as etapas dessa metodologia em um módulo de ensino.

Palavras-chaves: educação a distância, educação permanente, metodologia da problematização.

\section{THE CHALLENGE OF THE CONTINUOS LEARNING COURSE CONCEIVE WITHIN THE DISTANCE EDUCATION MODE BY METHODOLOGY THE APPLICATION OF THE PROBLEMATIZATION}

\begin{abstract}
The problematization methodology is made of an active methodology that makes it possible to improve the student's capacity, in reference to his/her role as an agent of participation and social transformation, in the perception of real problems and in the search of original and creative solutions. In order to investigate the use of the methodology of the problematization in the distance learning education model within the continuous learning process, a course concerning HIV subject has been developed for health professionals with the focus on the social practice. This article presents the challenging that is made by the application of the problematization methodology in the distance learning education model with the description and the analysis of the steps of this methodology under the learning-teaching mode guidelines.
\end{abstract}

Keywords: distance education, authorship, education continuing, methodology.

\section{Introdução}

A necessidade de continuar o processo de qualificação profissional após o término da graduação nas diversas áreas de formação em saúde é essencial para o bom desempenho profissional e atendimento das necessidades sociais. No momento do diagnóstico de doenças estigmatizantes, como no caso de infecção pelo Vírus da Imunodeficiência Humana (HIV), o processo de trabalho deve ser bem elaborado, pois envolve o ser humano em situação de vulnerabilidade e as ações repercutem diretamente na recuperação de seu bem estar físico e mental.

O papel de educador na saúde exige, além do domínio científico, o entendimento da necessidade do emprego de uma metodologia adequada à proposição da intervenção educacional nas suas diversas formas de apresentação. A utilização da modalidade de 
Educação a Distância (EAD) pode ser eficiente para aprimorar as competências profissionais através da educação permanente. O tipo de abordagem educacional na EAD encontra-se refletido no material instrucional eleito e o modelo educacional adotado fica implícito através da forma como as Tecnologias de Informação e Comunicação (TIC) são utilizadas (Feijó, 2010). Por isso, destaca-se a necessidade de fomento de estudos sobre o universo amplo de possibilidades de emprego de diferentes metodologias de ensino na elaboração de objetos de aprendizagem abordando educação na saúde.

A UNA-SUS foi criada para atender às necessidades de capacitação e educação permanente dos profissionais do Sistema Único de Saúde (SUS) no Brasil, na modalidade EAD. Fica implícito que para atender estas necessidades exige-se conhecer o público alvo da intervenção educacional, as competências necessárias para o melhor aproveitamento da modalidade e a percepção do mesmo sobre a metodologia empregada.

Deste modo, os autores deste artigo em consonância com estas políticas públicas e atuando em diversas frentes na primeira turma de Mestrado Profissional de Ensino na Saúde da Universidade Federal de Ciências da Saúde de Porto Alegre (UFCSPA) desenvolveram um Objeto de Aprendizagem (OA) que foi ofertado no ambiente virtual de aprendizagem (AVA) do curso de Especialização de Saúde da Família UNASUS/UFCSPA como um módulo optativo. Para conceber este módulo foi utilizada a Metodologia da Problematização (MP), com foco na prática social do manejo dos pacientes com resultado do teste rápido reagente para o vírus do HIV. A justificativa pela escolha do tema, além de considerar a pandemia mundial da infecção pelo vírus, o seu entorno de preconceitos e de vulnerabilidades, baseia-se na Portaria $\mathrm{n}^{\mathrm{o}} \underline{3.275}$, de 26 de dezembro de 2013. Esta estabelece, pela primeira vez, que a formação dos profissionais sobre aplicação dos testes rápidos do HIV poderá ocorrer por meio de cursos de ensino à distância. $\mathrm{O}$ objetivo deste artigo é relatar o desafio que se constitui o uso da Metodologia da Problematização na modalidade de educação à distância na educação permanente, enfatizando o emprego inovador da Metodologia da Problematização em um módulo formativo de educação permanente ministrado na modalidade EAD.

Este artigo encontra-se organizado em cinco seções, incluindo a introdução e conclusão. A seção 2 apresenta a MP, a seção 3 aborda material e métodos, na seção 4 é apresentado o objeto, a descrição dos resultados e discussão do uso da MP na concepção do módulo formativo para educação permanente a ser ministrado na modalidade EAD.

\section{Metolologia da Problematização}

Segundo Berbel (2012), autora da metodologia, a MP associa-se ao construtivismo, à dialética, de onde extraiu sua noção de práxis, e, à pedagogia libertadora de Paulo Freire. O ponto de partida é a vivência da situação popular. Esta ajudaria a identificar os principais problemas e realizar a escolha de temas geradores, cuja problematização levaria à conscientização, que redundaria na ação social e política. Esse processo apresenta razoável proximidade com as etapas do Arco de Maguerez.

De acordo com Berbel (1999), a primeira inferência para a Metodologia da Problematização (MP) é o Método do Arco (conforme a figura 1), de Charles Maguerez, apresentado por Bordenave e Pereira em 1982. Segundo Bordenave (1983), 
o importante é o aumento da capacidade do aluno, na postura de agente participativo de transformação social, para detectar os problemas reais e buscar para eles soluções originais e criativas. Um problema nesta metodologia é definido como um problema que não possui resposta pronta.

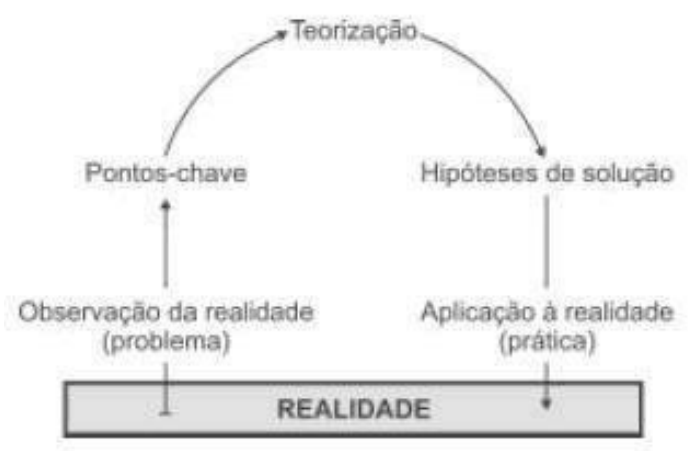

Figura 1- Arco de Maguerez

Fonte: Berbel (2012)

Assim a MP está estruturada em cinco etapas consecutivas, tendo como base a realidade. São elas: observação da realidade; levantamento de pontos-chave; teorização; hipótese de solução e aplicação à realidade.

A MP parte do pressuposto que a prioridade é potencializar a participação e ação do aluno na transformação social, detectando problemas reais e buscando para eles respostas originais e criativas. Neste contexto, a premissa é saber fazer perguntas relevantes em qualquer situação, para compreendê-las e saber manejá-las adequadamente. Se a teorização for bem sucedida, como proposto por Maguerez, os alunos compreendem não somente as manifestações empíricas ou situacionais, mas também os princípios teóricos que o explicam, permitindo o crescimento mental dos alunos (Bordenave, 1983).

A escolha por trabalhar com soluções de problemas repercute em grandes transformações comparadas a outras metodologias. Na MP o docente passa de transmissor de informações para provocador da busca de informação, atuando como apoiador e parceiro na busca e construção do conhecimento. No entanto, o aluno não aprende sozinho, tem a mediação do professor (Berbel, 1998). A MP insere práticas que visam à transformação social através de ações conscientizadoras e críticas, caracterizando-se por uma educação libertadora e emancipatória (Cyrino 2004). Cyrino (2004), ainda ressalta a relação da MP com a Aprendizagem Baseada em Problemas (ABP), pois ambas têm em comum uma pergunta focal: o que está acontecendo? Todavia, os pressupostos, os pontos de partida, e a estrutura dos trabalhos desenvolvidos são distintos. Na ABP, o problema é apresentado pelo professor-tutor e às vezes pode ficar um pouco longe da realidade, enquanto que na MP é apresentada a realidade. Reichert e Costa (2005) apresenta a Metodologia dos Desafios desenvolvida pelo SENAI, que foi baseada na MP e na ABP, em um ambiente virtual de aprendizagem que promove a construção do conhecimento de forma autônoma e colaborativa, contudo mesmo o ponto de partida sendo uma situação problema comum às turmas dos alunos, as trajetórias das aprendizagens podem ser diferentes, decorrentes de suas histórias pessoais e estruturas pré-existentes do grupo. 
Perante estas questões e abordagens metodológicas, considera-se um diferencial significativo a escolha da MP para abordar a delicada temática do manejo inicial do paciente com diagnóstico de HIV através do teste rápido na realidade da Atenção Primária em Saúde.

\section{Material e Métodos}

O método de pesquisa utilizado foi composto de pesquisa bibliográfica, observação in loco e prototipação do objeto de aprendizagem focado em competências. A concepção do módulo iniciou com o estudo sobre o emprego da MP e suas possíveis aplicações na EAD. A seguir, ocorreu a pesquisa dos materiais instrucionais que contemplassem a seleção de conteúdo. O caráter interacionista da metodologia influenciou na decisão da seleção e concepção do OA. A escolha dos recursos transparece a estratégia de ensino das metodologias ativas de motivar o educando, pois perante o problema, ele se detém, examina, reflete, relaciona a sua vivência e articula suas descobertas, as ressignificando à realidade proposta (Mitri, 2008).

A seguir, ocorreu a elaboração do plano pedagógico com objetivo de organizar o módulo nas etapas conforme os preceitos de Berbel (1999), contando com apoio da equipe pedagógica do UNA-SUS/UFCSPA. O desenvolvimento do roteiro ou storyboard exerceu o papel importante de comunicação entre o conteudista da área da saúde e a equipe de design do UNA-SUS/UFCSPA, no desenvolvimento da qualidade de reutilização e da interoperabilidade do OA. O trabalho conjunto garantiu que o módulo, apesar de ser optativo, mantivesse o alinhamento ao perfil dos alunos da instituição.

\section{Resultados e Discussão}

Na construção do OA em questão, processo referendado em Berbel (1998 e 2011), a partir de observação da realidade elaborou-se a situação problema. No módulo (conforme apresentado na Figura 2) a situação problema é apresentada num caso clínico contextualizado em uma cidade fictícia, chamada Santa Fé, localizada imaginariamente no interior do sul do Brasil. A contextualização através de caso clínico complexo e da cidade fictícia faz parte da proposta pedagógica do Curso de Especialização em Saúde da Família UNA-SUS/UFCSPA, na modalidade EAD (Dahmer et al, 2014). O caso clínico complexo apresenta um enredo envolvendo a cidade, como uma entrevista na Rádio Santa Fé com a secretária de saúde, notícia na Gazeta da cidade e o Banner que fica disposto na frente da Unidade de Atendimento (Virtual).

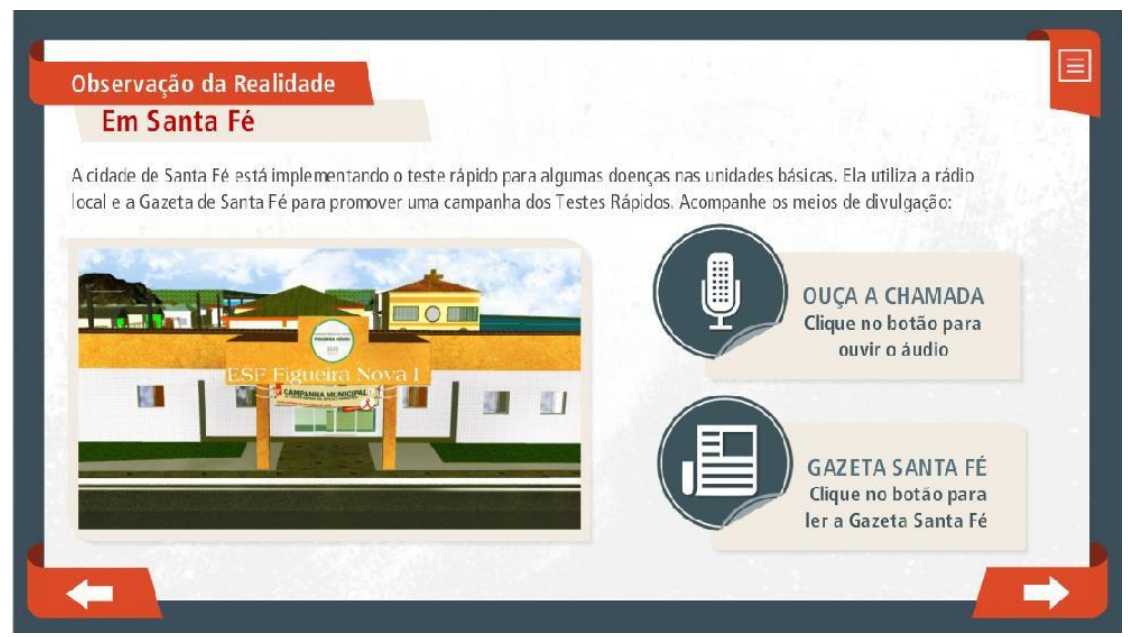


Figura 2- Na Observação da Realidade, a riqueza dos detalhes da campanha.

Fonte: Autores em parceria com a equipe do UNA-SUS/ UFCSPA.

A realidade do ambiente profissional do aluno aparece já na primeira atividade do módulo, em que o aluno se apresenta e divide com os colegas como ele percebe a prática do teste rápido para o HIV dentro da sua unidade de saúde, como apresenta a Figura 3. Este primeiro momento ocorre antes da leitura do caso clínico, junto com a ilustração de uma conversa através de mensagens instantâneas. O caso clínico ocorre na realidade fictícia do território já apresentado em módulos anteriores no curso, com a cidade, os personagens e a rede de assistência já contextualizados na plataforma.

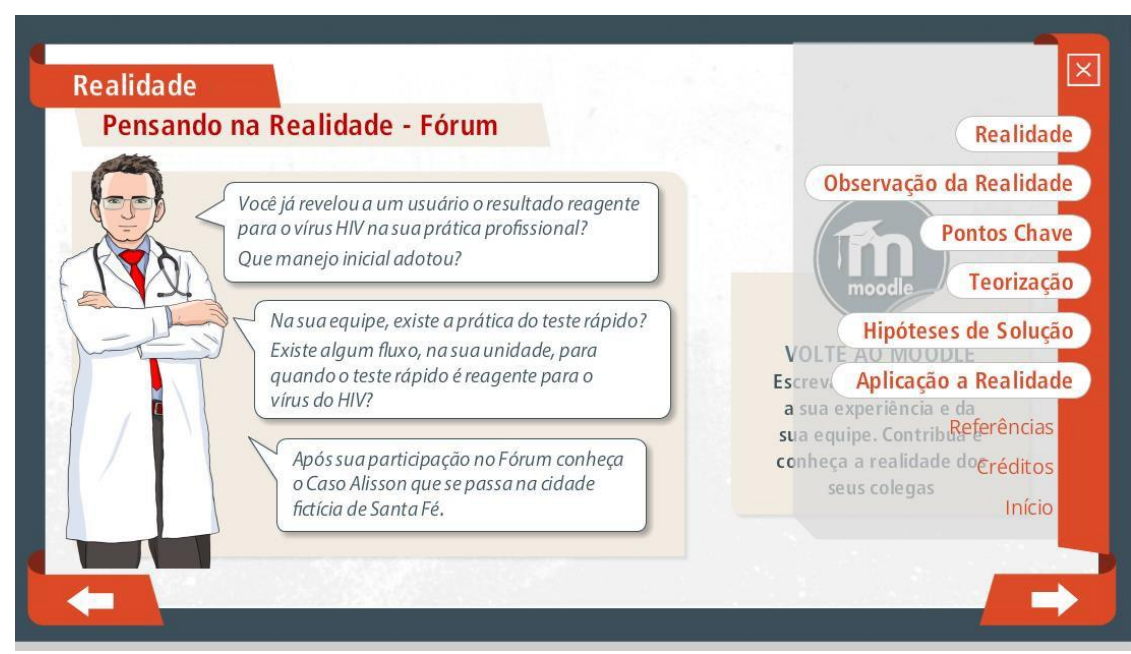

Figura 3- Menu lateral do Módulo organizado pelas etapas da MP.

Fonte: Autores em parceria com a equipe do UNA-SUS/ UFCSPA.

A barra de menu lateral divide a estrutura do Módulo conforme a realidade e as etapas da MP, sendo que no início é exposto ao aluno que está sendo aplicada esta metodologia de ensino diferente da que comumente é utilizada no AVA da UNA-SUS/ UFCSPA.

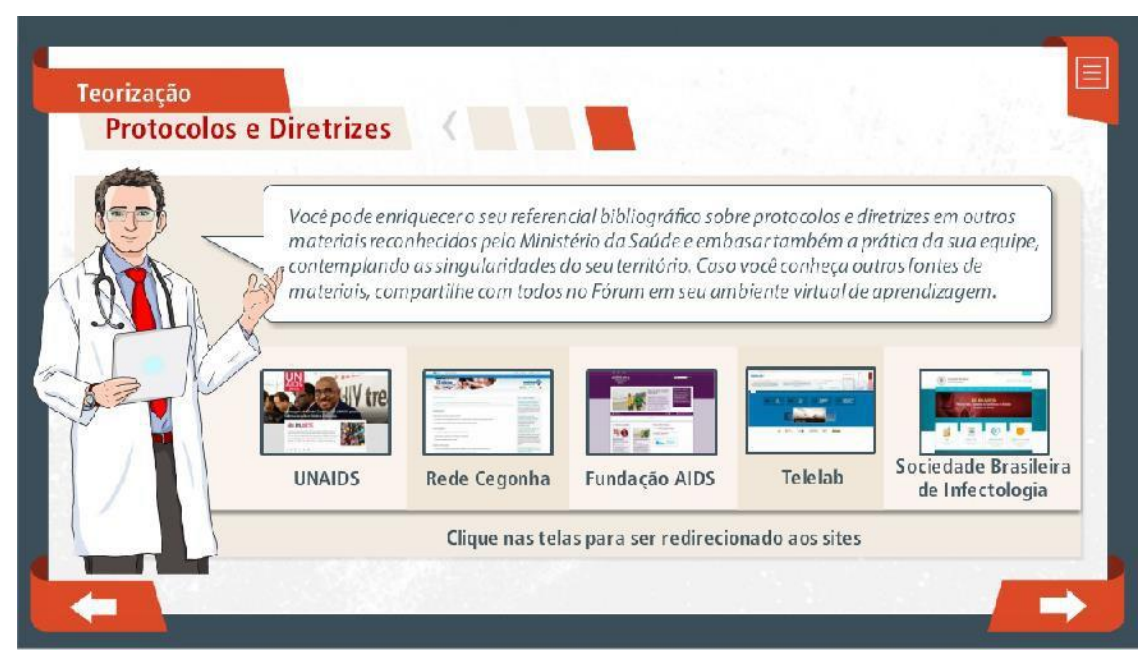

Figura 4- Na Teorização, redirecionamento para sites de pesquisa.

Fonte: Autores em parceria com a equipe do UNA-SUS/ UFCSPA.

A proposta da metodologia é que o aluno desenvolva autonomia para pesquisar quando estiver enfrentando um problema e desenvolver soluções para modificar esta situação. Para tanto, parte do referencial teórico constitui-se na pesquisa do próprio aluno a 
reconhecidos sites com publicações sobre as diretrizes do HIV, como apresentado na Figura 4.

Para melhor visualização da estrutura do módulo em relação à aplicação de cada etapa da metodologia da problematização organizou-se a tabela 1.

Tabela 1- A disposição da apresentação do módulo conforme as etapas da MP.

\begin{tabular}{|c|c|c|}
\hline $\begin{array}{l}\text { Etapas da } \\
\text { MP }\end{array}$ & Forma de apresentação no módulo & $\begin{array}{l}\text { Objetivo a ser alcançado e atividade a } \\
\text { ser desenvolvida }\end{array}$ \\
\hline $\begin{array}{l}\text { Observação da } \\
\text { realidade }\end{array}$ & $\begin{array}{l}\text { Caso clínico ambientado na unidade de } \\
\text { saúde, apresentando a interação entre os } \\
\text { diversos atores, incluindo uma } \\
\text { representação ilustrativa do diálogo entre } \\
\text { o corpo clínico, via whatsapp. } \\
\text { Proposta de fórum de discussões para que } \\
\text { os alunos apresentem sua visão sobre o } \\
\text { problema relatado no caso clínico e suas } \\
\text { reflexões sobre o funcionamento de sua } \\
\text { equipe de trabalho, possibilitando a troca } \\
\text { de informações e percepções sobre o } \\
\text { tema. }\end{array}$ & $\begin{array}{l}\text { Objetivo: Observar a realidade através da } \\
\text { situação problema, refletindo sobre as } \\
\text { similaridades e os contrastes do seu } \\
\text { universo de trabalho. } \\
\text { Atividade: participação no fórum } \\
\text { relatando a realidade constatada a partir } \\
\text { de diferentes ângulos (para além da parte } \\
\text { científica, também o foco na } \\
\text { humanização ao acolher este paciente). O } \\
\text { debate visa estimular nos alunos o olhar } \\
\text { atento e o registro do que percebem. }\end{array}$ \\
\hline Pontos Chave & $\begin{array}{l}\text { Apresentação de um jogo para edificar a } \\
\text { lista de problemas pré-determinados } \\
\text { conforme a graduação de prioridades, } \\
\text { visando a enumeração por ordem de } \\
\text { importância dos pontos chave do caso } \\
\text { apresentado. }\end{array}$ & $\begin{array}{l}\text { Objetivo Definir pontos chave } \\
\text { importantes. } \\
\text { Atividade: listagem dos pontos definidos } \\
\text { como realmente importantes, iniciando o } \\
\text { processo de reflexão sobre as possíveis } \\
\text { causas do problema, diretas e indiretas, } \\
\text { procurando entender o contexto como } \\
\text { todo. }\end{array}$ \\
\hline Teorização & $\begin{array}{l}\text { Disponibilização de literatura sobre o } \\
\text { manejo do paciente com diagnóstico de } \\
\text { HIV na Atenção Primária em Saúde. São } \\
\text { apresentadas sugestões dos principais sites } \\
\text { oficiais sobre a temática. Através do } \\
\text { fórum é possível que o aluno contribua } \\
\text { indicando outras referências contribuindo } \\
\text { com o grupo. O referencial teórico é } \\
\text { composto por repositórios: animação na } \\
\text { forma de vídeo sobre a replicação viral, } \\
\text { publicações textuais e uma apresentação } \\
\text { em PowerPoint. }\end{array}$ & $\begin{array}{l}\text { Objetivo: Estimular os alunos a } \\
\text { participarem ativamente na busca de } \\
\text { referenciais, para aprenderem a realizar } \\
\text { esse processo quando for necessário na } \\
\text { sua rotina laboral. } \\
\text { Atividade (avaliativa): Antes e depois da } \\
\text { teorização são propostas atividades para } \\
\text { avaliar os saberes envolvendo a prática do } \\
\text { teste rápido. O tutor atua como mediador } \\
\text { e não como quem fornece todas as } \\
\text { informações ou autoria dos processos } \\
\text { decisórios. }\end{array}$ \\
\hline $\begin{array}{l}\text { Hipóteses de } \\
\text { solução }\end{array}$ & $\begin{array}{l}\text { Pergunta semi-estruturada com as } \\
\text { possíveis soluções aos pontos chave } \\
\text { elencados (hipóteses), para que após a } \\
\text { reflexão das três etapas anteriores } \\
\text { respondam mobilizando outros } \\
\text { integrantes da sua equipe e a rede de } \\
\text { apoio aos serviços de saúde. }\end{array}$ & $\begin{array}{l}\text { Objetivo: promover a compreensão e } \\
\text { estimular a formulação de hipóteses } \\
\text { criativas e inovadoras com toda a rede de } \\
\text { apoio social e assistencial para } \\
\text { solucionar impasses. } \\
\text { Atividade (avaliativa): dissertar sobre as } \\
\text { possibilidades de resolução dos } \\
\text { problemas, demonstrando se está } \\
\text { sensibilizado com todo o contexto da } \\
\text { situação problema. }\end{array}$ \\
\hline
\end{tabular}




\begin{tabular}{|l|l|l|}
\hline $\begin{array}{l}\text { Aplicação à } \\
\text { realidade }\end{array}$ & $\begin{array}{l}\text { Elaboração de uma proposta de } \\
\text { fluxograma com manejo inicial do } \\
\text { usuário com resultado reagente para o } \\
\text { vírus do HIV dentro da sua realidade da } \\
\text { sua unidade de saúde, preferencialmente } \\
\text { com sua equipe de trabalho. }\end{array}$ & $\begin{array}{l}\text { Objetivo: possibilitar organizar o } \\
\text { planejamento das decisões para } \\
\text { transformar a conduta assistencial. } \\
\text { Atividade (avaliativa): o aluno constrói } \\
\text { um instrumento para intervir na realidade } \\
\text { local através das transformações da } \\
\text { prática. O sistema de cooperação para } \\
\text { realizar a proposta coletiva, apresenta } \\
\text { redução da necessidade de um líder. O } \\
\text { seu emprego possibilita modificar a } \\
\text { realidade inicialmente observada no } \\
\text { fórum. }\end{array}$ \\
\hline
\end{tabular}

$\mathrm{Na}$ escolha dos materiais instrucionais preferiu-se selecionar os protocolos e apresentações internacionais de fontes reconhecidas na pesquisa do HIV como a Organização Mundial da Saúde, UNAIDS e da Rede Cegonha. A utilização de vários OAs para compor um OA maior, que é o módulo de intervenção, está de acordo com os recursos educacionais priorizando o desenvolvimento da qualidade de reutilização, da interoperabilidade e do alinhamento da ação educacional com o perfil dos alunos inscritos na rede UNA-SUS (Brasil, 2013). Com o intuito de contemplar os pontos chave, existe ainda o estímulo para o aluno explorar as potencialidades do seu núcleo profissional e ampliar a teorização trazendo os fluxos possíveis da rede de apoio ao cuidado do usuário.

Behar (2012) analisou o perfil do aluno, sujeito desse processo em EAD, e a necessidade de novas possibilidades educacionais com o desenvolvimento de competências para propor ações e mudanças. A partir da fala de alunos, organizou de forma gradual doze competências necessárias para o uso de EAD, sendo elas administração do tempo, fluência digital, autonomia, comunicação, reflexão, organização, planejamento, presencialidade virtual, autoavaliação, automotivação, flexibilidade e trabalho em equipe. No módulo aqui apresentado, a estimativa para realização é de oito horas e as competências mais requeridas são reflexão, autonomia, comunicação e trabalho em equipe.

O pensamento criativo dos alunos é estimulado, em cada etapa do processo, incluindo a etapa final do arco, a aplicação à realidade. Neste momento, é requerido ao aluno a construção de um fluxograma prevendo as possibilidades do atendimento integrado ao paciente que receba o teste rápido reagente para o Vírus do HIV dentro da Atenção Primária de Saúde. O aluno é estimulado a fazer esta construção de forma coletiva com sua equipe de trabalho e explorando todas as singularidades da rede de apoio existentes no seu território. $\mathrm{O}$ atendimento pode ocorrer de forma integrada e compartilhada com diversas esferas de serviço, permanecendo a Atenção Primária responsável pela linha de cuidado.

Embora a estrutura do arco permaneça constante, sua aplicação é flexível, por adaptarse às circunstâncias, na modalidade EAD. A interação do aluno com a intervenção é alta em todas as etapas do Arco, favorecendo um comprometimento com o processo de transformação da realidade. Soma-se que a perspectiva de padronizar conteúdos educacionais para formação permanente aos profissionais de saúde a serem disponibilizados à longa distância pode evitar distorção na replicação destes aos seus pares, contribuindo para uma prática mais atualizada (Hoyos, 2013). Considerando a característica de reutilização dos OAs, não são necessários construí-los para cada intervenção, podendo selecionar um ou alguns já existentes para utilização parcial, ou totalmente para desenvolver as competências requeridas. Konrath (2009) descreve a 
perspectiva teórica que embasa o OA, através da experiência de "Nós no mundo", com um plano pedagógico com intencionalidades e fundamentação teórica para que o trabalho seja significativo e prazeroso, aprendendo através das interações entre professor e alunos. Neste caso, ratificou-se que o OA pode direcionar o trabalho pedagógico pensado pelo professor.

No nosso módulo, a escolha da temática HIV e da MP organiza o OA e sua última atividade proposta, elaboração de um fluxograma de atendimento ao usuário com teste rápido reagente para HIV, possibilita que o aluno transforme a sua prática de trabalho junto à rede de apoio na sua unidade de saúde, (re) significando a realidade de acordo com a MP, o que vai ao encontro dos objetivos apresentados por Berbel (2011), que são desenvolver o espírito científico, o pensamento crítico, o pensamento reflexivo e os valores éticos entre outras competências. A valorização desses aspectos na formação dos profissionais é encontrada nas Diretrizes Curriculares Nacionais, que apontam a importância do desenvolvimento da capacidade de aprender continuamente na formação e na prática, aprendendo a aprender com a cooperação por meio de redes (Ceccim,2008).

Para contemplar a coleta de dados sobre o perfil do aluno que está realizando o referido módulo, é aplicado um questionário para levantamento de dados pessoais, do ambiente de trabalho e da percepção do aluno em vivenciar pela primeira vez a MP no curso de especialização de Saúde da Família UNA- SUS/UFCSPA. O módulo encontra-se disponível na Plataforma Acervos de Repositórios Educacionais (ARES) sobre o registro 3473 (https://ares.unasus.gov.br/acervo/handle/ARES/3474).

\section{Conclusões}

O foco deste trabalho foi apresentar o desafio da aplicação da MP na formação permanente de profissionais da saúde, na modalidade EAD, relacionando suas contribuições na construção da autonomia dos sujeitos e possibilidades significativas de alteração na condução dos processos na realidade do atendimento e da saúde pública. A compreensão sobre o papel da EAD e a utilização da MP nesta modalidade destacam-se como possibilidades de contribuição efetiva no processo de educação permanente do profissional da saúde vinculado ao SUS.

A premissa da MP baseia-se na superação de obstáculos, através da identificação e construção de possibilidades de solução mediadas pelo professor. A etapa final da MP é o momento com maior potencial transformador, onde o aluno é estimulado a planejar estratégias reais que permitam ser postas em prática ou preparadas para tal. Assim, a MP apresenta um componente político e social à educação permanente, ao ressignificar o papel do profissional da saúde.

Como trabalhos futuros, inclui-se a utilização do Módulo formativo concebido sobre o tema HIV com uma turma de profissionais da área da saúde que participarão do curso na modalidade EAD, momento em que será possível avaliar o uso da Metodologia da Problematização com estes profissionais em Educação Permanente.

\section{Agradecimentos}

Agradecemos à Coordenação Geral, professoras Alessandra Dahmer e Maria Eugenia Bresolin Pinto, e ao Núcleo de Apoio Técnico do Projeto UNA-SUS/ UFCSPA, pelo apoio e contribuições no desenvolvimento do módulo. 


\section{Referências Bibliográficas}

BRASIL L.B.; SKELTON-MACEDO, C.; CAMPOS F.E.; HADDAD A.E. Objetos de aprendizagem, competências profissionais para profissionais de saúde e e-learning: estudos para desenvolvimento de uma taxonomia. Jornal Brasileiro TeleSSaúde. Rio de Janeiro, n.2, v.1, p.75-80, 2013.

BEHAR, P.A.; SILVA, K.K.A. Mapeamento de Competências: Um foco no aluno da Educação a Distância. Revista Renote. Porto Alegre, Jul. 2012. Disponível em: http://seer.ufrgs.br/renote/article/view/36395 Acesso em: 2 maio 2015.

BERBEL, N. A. N. A problematização e a aprendizagem baseada em problemas:

Diferentes termos ou diferentes caminhos? Interface Comunicação, Saúde Educação. Londrina, Fev. $1998 . \quad$ Disponível em: http://www.scielo.br/pdf/icse/v2n2/08 Acesso em: 20 ago. 2015.

BERBEL N. A. P. Metodologia da Problematização: Fundamentos e Aplicações. $2^{a}$ Edição. Londrina: Editora UEL, 1999.199p.

BERBEL, N. A. N. As metodologias ativas e a promoção da autonomia de estudantes. Semina: Ciências Sociais e Humanas. Londrina, Jan. 2011. Disponível em: http://www.uel.br/revistas/uel/index.php/seminasoc/article/view/10326 Acesso em: 20 ago. 2015.

BERBEL N. A. N. A metodologia da problematização com o Arco de Maguerez: uma reflexão teórico-epistemológica. Londrina: EDUEL, 2012. 204p.

BORDENAVE, J. E. D. Alguns Fatores Pedagógicos. Texto adaptado do artigo: La transferencia de tecnologia apropriada al pequenô agricultor. Rev I Educ Adultos, v.3, n.1-2, p.261- 268, 1983.

CECCIM, R.B. A emergência da educação e ensino da saúde: interseções e intersetorialidades. Ciência \& Saúde. Porto Alegre, Jan. 2008. Disponível em: http://revistaseletronicas.pucrs.br/ojs/index.php/faenfi/article/view/3859/2936

Acesso em: 2 set. 2015.

CIRYNO, E.G.; TORALLES- PEREIRA, M.L. Trabalhando com estratégias de ensino aprendizado por descoberta na área da saúde: a problematização e a aprendizagem baseada em problemas. Caderno de Saúde Pública. Rio de janeiro, Jun. 2004. Disponível

em:

http://www.scielo.br/scielo.php?script=sci_arttext\&pid=S0102311X2004000300015 Acesso em: 12 jun. 2015.

DAHMER, A.; PINTO, M. E. B.; COSTA, M. R.; PINHEIRO, L. B. O uso de cidades virtuais e diversidade midiática como estratégias pedagógicas em um curso a distância de saúde da família. IN: GUSMÃO, C. M. G (Org.). Relatos do uso de Tecnologias Educacionais na Educação permanente de profissionais da saúde no Sistema Universidade Aberta do SUS. Recife: Ed. Universitária da UFPE, 2014. p. 216-241.

FEIJÓ, E. F.; TAVARES C. M. M. Long Distance Education: Estimated TheoreticalMethodological of the Nursing Education. Revista Enfermagem UFPE on line. Pernambuco, Jul. 2010. Disponível em:

http://www.revista.ufpe.br/revistaenfermagem/index.php/revista/article/viewArticle/93 5 Acesso em: 25 set. 2015. 
HOYOS, J. Preferred HIV testing services and programme characteristics among clients of a rapid HIV testing programme. BMC Public Heathy. Inglaterra, Aug. 2013. Disponível em: http://www.ncbi.nlm.nih.gov/pmc/articles/PMC3765864/ Acesso em: 4 maio 2015.

KONRATH, M.L.P.; CARNEIRO, M.L.F.;TAROUCO, L.M.R. Estratégias pedagógicas, planejamento e construção de Objetos de Aprendizagem para uso pedagógico. Renote. Porto Alegre, Jun. 2009. Disponível em: http://seer.ufrgs.br/renote/article/view/14079 Acesso em: 10 abr. 2016.

MITRI, S. M.; et al. Metodologias ativas de ensino-aprendizagem na formação profissional em saúde: debates atuais. Ciências\& Saúde Coletiva. Rio de Janeiro, Dez. 2008.

Disponível em: http://www.scielosp.org/scielo.php?script=sci_arttext\&pid=S1413812320080009000

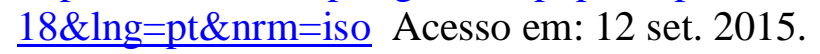

REICHERT, C.L.; COSTA, J.S. Metodologia dos Desafios: problematização e sentido em ambientes virtuais de aprendizagem. Renote. Porto Alegre, Mai. 2005. Disponível em: http://seer.ufrgs.br/index.php/renote/article/view/13804 Acesso em: 10 abr. 2016. 